\title{
First report of Fusarium incarnatum causing rot disease on lotus in China
}

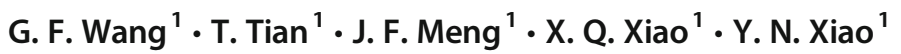 \\ Received: 24 September 2019 / Accepted: 3 December 2019 /Published online: 17 December 2019 \\ (C) Società Italiana di Patologia Vegetale (S.I.Pa.V.) 2019
}

Keywords Fusarium incarnatum $\cdot$ Nelumbo nucifera $\cdot$ Lotus rot disease

Lots of lotus (Nelumbo nucifera) with the typical symptoms of lotus rot disease, i.e. withered leaf edge and lesions of which were irregularly shaped and dark brown, were found in several fields located in Wuhan in 2017. Symptomatic lotus leaves were collected. Leaf tissues on the lesion boundaries were obtained, surface-sterilized with $70 \%$ ethanol for $30 \mathrm{~s}$, and $0.1 \%$ mercuric chloride solution for $2 \mathrm{~min}$. After rinsing in sterile water, segments were plated on synthetic nutrient-poor agar, cultured at $25{ }^{\circ} \mathrm{C}$. Pure cultures were identified as Fusarium incarnatum on the basis of morphological features including the white thick hyphae, multicelluar macroconidia that are falculate, 3 to 5 septate produced in monophialide sporodochia, and the chlamydospores borned in chains (Leslie and Summerell 2006). The translation elongation factor- $1 \alpha$ (EF-1 $\alpha)$ and DNA-directed RNA polymerase II subunit 2 (RPB2) of three representative isolates were amplified with primer pairs efl/ef2 (Geiser et al. 2004) and 5F2/7cR (O'Donnell et al. 2008), and sequenced. BLAST searches revealed that EF-1 $\alpha$ (MK049899) and RPB2 (MK049900) was both $99 \%$ identical to F. incarnatum (KR003731 and JX885465, respectively) in GenBank, as well as $100 \%$ and $99 \%$ to F. incarnatum-equiseti species complex (NRRL34059 and NRRL26417, respectively) in the FusariumID database, respectively. The pathogenicity of the isolate was assayed on lotus plants which were grown in sterilized soil at
$25{ }^{\circ} \mathrm{C}$ for 6 days under humid conditions. Lotus plants were inoculated by injecting conidial suspension (200 spores/plant) into the bases of petioles and the rhizomes of lotus, using plants without inoculation as control. After 6 days, typical symptom of withered leaf edge and lesions appeared on inoculated lotus leaves, and $F$. incarnatum was successfully re-isolated from symptomatic tissues. To our knowledge, this is the first report of $F$. incarnatum causing rot disease on lotus in China.

\section{References}

Geiser DM, Jiménez-Gasco MM, Kang S, Makalowska I, Veeraraghavan N, Ward TJ, Zhang N, Kuldau GA, O'Donnell K (2004) FUSARIUM-ID v. 1.0: A DNA Sequence Database for Identifying Fusarium. Eur J Plant Pathol 110: 473-479

Leslie JF, Summerell BA (2006) The Fusarium laboratory manual. Blackwell Publishing, Oxford

O’Donnell K, Sutton DA, Fothergill A, McCarthy D, Rinaldi MG, Brandt ME, Zhang N, Geiser DM (2008) Molecular phylogenetic diversity, multilocus haplotype nomenclature, and in vitro antifungal resistance within the Fusarium solani species complex. J Clin Microbiol 46: 2477-2490

Publisher's note Springer Nature remains neutral with regard to jurisdictional claims in published maps and institutional affiliations.

Y. N. Xiao

xiaoyannong@mail.hzau.edu.cn

1 Key Laboratory of Plant Pathology of Hubei Province, College of Plant Science \& Technology, Huazhong Agricultural University, Wuhan 430070, China 